\title{
LANGERHANS' CELL GRANULOMA CONFINED TO THE BILE DUCT
}

\author{
Laura S. Finn, MD, and Ronald Jaffe, MB, BCh $\square$ Department of Pathology, \\ Children's Hospital of Philadelphia, and Department of Pathology, Children's Hospital of \\ Pittsburgh, Pennsylvania, USA
}

\begin{abstract}
ㅁ Langerhans' cell histiocytosis (LCH) of the liver is uncommon. When seen, it is part of multifocal disease and can present as biliary obstruction. We present a case of sclerosing biliary disease with a solitary LCH lesion and no evidence of systemic disease. We postulate that the LCH is a secondary phenomenon, arising against a background of a complex, familial liver disease. This case also raises the possibility that some instances of idiopathic sclerosing cholangitis may follow cryptic LCH of the bile ducts.
\end{abstract}

Keywords bile duct, Langerhans' cell histiocytosis, liver, sclerosing cholangitis

Langerhans' cell histiocytosis is a monoclonal proliferation of histiocytes similar in phenotype to dendritic Langerhans' cells [1]. The spectrum of disease varies from single bone involvement (eosinophilic granuloma) to a disseminated and sometimes fatal syndrome. Over the past few years it has become clear that Langerhans' cell histiocytosis ( $\mathrm{LCH}$ ) can affect the liver with a propensity for damage to the major bile ducts that results in sclerosing cholangitis and, eventually, biliary cirrhosis. These patients have all had biliary involvement as part of a multifocal LCH with recorded disease in the skin, lymph nodes, and bone and clinical diabetes insipidus [2-7].

We describe a child who was jaundiced at birth and who, in the absence of documented extrahepatic involvement, had a solitary Langerhans' cell lesion found in the extrahepatic bile duct at $2 \frac{1}{2}$ years of age.

\section{CASE REPORT}

This $2 \frac{1}{2}$-year-old female was the third offspring, born full term at $3700 \mathrm{~g}$ to consanguineous Greek parents. She was jaundiced at birth and was re-

Received 22 January 1996; accepted 19 April 1996.

The authors wish to thank Dr. Athanassious C. Tsamandas for his assistance in translation and obtaining original biopsy material. Rocco Agostini, Jr., provided the electron micrograph.

Address correspondence to R. Jaffe, MB, BCh, Department of Pathology, Children's Hospital of Pittsburgh, 3705 Fifth Avenue, Pittsburgh, PA 15213, USA. 
ported to have developed acholic stools. Radionucleotide imaging and exploratory laparotomy with in traoperative cholangiogram, done in Greece at 40 days of age, were reportedly within normal limits. A wedge biopsy of the liver, reviewed here, showed micronodular cirrhosis and a mild, mixed inflam matory cell infiltrate around portal triads. There was marked canalicular and cholangiolar cholestasis with bile plug formation. Occasional ductules surrounding portal areas and along the fibrous septa had dilated and complex profiles reminiscent of a ductal plate malformation. S-100-reactive histiocytes were not identified when stained retroactively. Over the next 2 years her liver function tests remained elevated with maximal values as follows: alkaline phosphatase, $945 \mathrm{IU} / \mathrm{L}$; aspartate aminotransferase (AST), $328 \mathrm{IU} / \mathrm{L}$; alanine am in otransferase (ALT) 253, IU / L, $\gamma$-glutamyltransferase, $1089 \mathrm{IU} / \mathrm{L}$; total bilirubin, $9.8 \mathrm{mg} / \mathrm{dL}$. U rine osmolality was normal. She had no skin lesions or lymphadenopathy. She developed hepatosplenomegaly, ascites, and pruritus and underwent orthotopic liver transplantation at $2 \frac{1}{2}$ years of age. The explanted liver weighed $724 \mathrm{~g}$ and had a nodular surface. The gallbladder and cystic duct were unremarkable. Microscopic examination showed a micronodular biliary cirrhosis with thick collagenous septa separating parenchymal nodules; cholestasis was minimal. Ductal proliferation was variable but generally quite striking and typically associated with a mild lym phocytic infiltrate; only rarely did the ductules assume a convoluted configuration. Most portal areas were densely sclerotic and had several arteries unaccompanied by bile ducts. Interlobular ducts were surrounded by collagenous or cellular concen tric fibrosis. The right hepatic duct was segmentally dilated and had a prominent fibrocollagenous wall. A densely cellular infiltrate invaded the thickened wall, focally destroying the epithelium and obliterating the lumen of the left hepatic duct and its first-order branches (Figure 1a). The majority of cells were histiocytes with grooved and folded nuclei and eosinophilic cytoplasm; Birbeck granules were identified by electron microscopy (Figure 1b and c). Antibodies to S-100 and HLA-DR (LN3) stained the histiocytes intensely. The monoclonal antibody $\mathrm{O} 10$, which recognizes a formalin-resistant epitope of CD 1a [8], marked the same cells. HLA-DR, in addition, highlighted sinusoidal lining cells and some of the large duct epithelium less in timately associated with histiocytes. Lymphocytes, neutrophils, and numerous eosinophils were associated with the histiocytes. Langerhans' cells were not identified in the parenchyma, peripheral triads, or hilar lymph node. Portal vein branches had signs of hypertension including myxoid changes and eccentric myointimal proliferation. The gallbladder had mild chronic changes. Follow-up of $2 \frac{1}{2}$ years has not revealed evidence of other overt LCH lesions.

Her family history is significant. The second child in this sibship was a girl, reported to have died in the neonatal period of "liver failure." A 


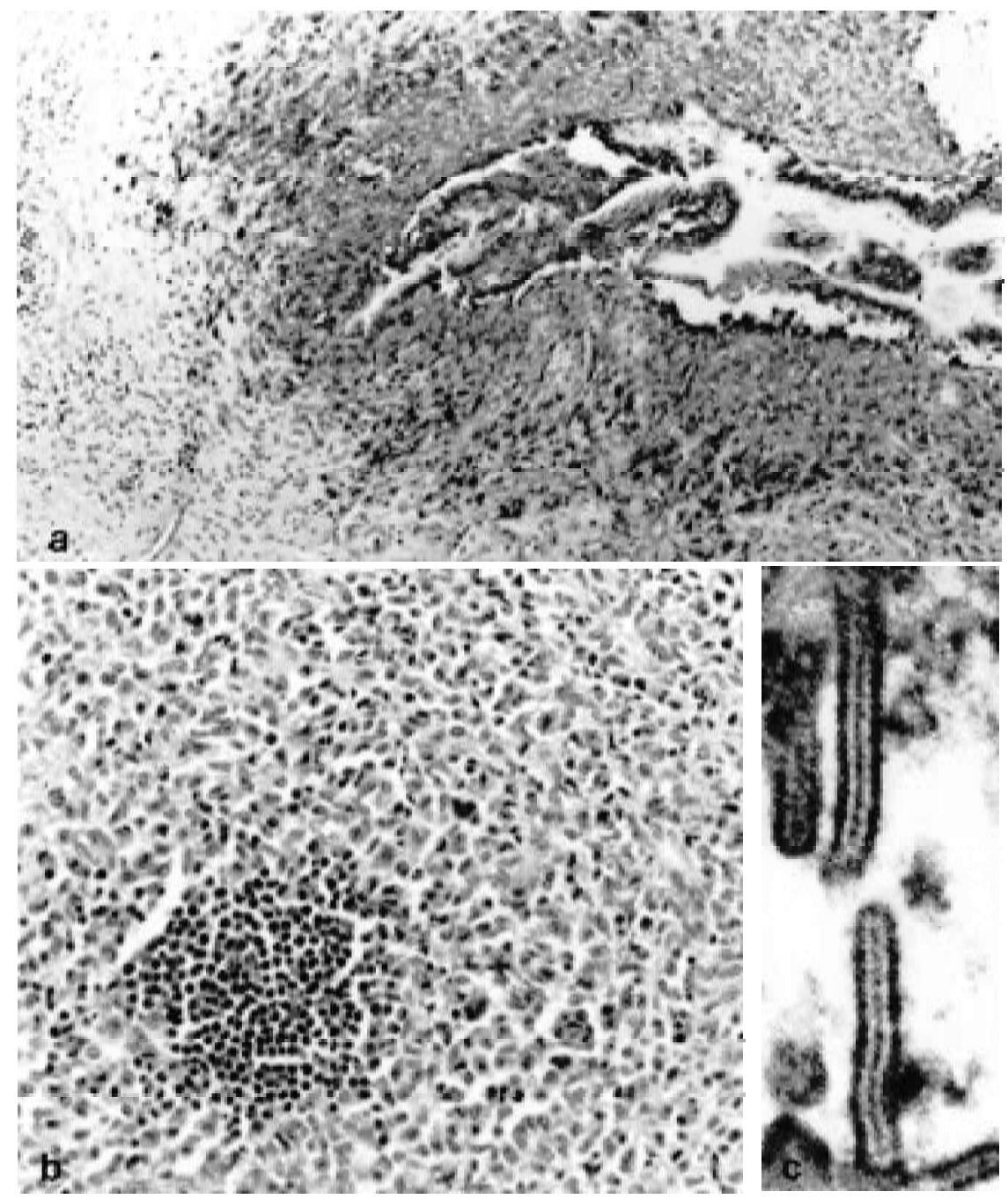

Figure 1. (a) CD la strongly stains the cellu lar infiltrate that surrounds the bile duct and destroys epithelium. $\mathrm{DAB} \times 100$. (b) The infiltrate has a monomorphous population of cytoplasm-rich histiocytes that have grooved and fold ed nuclei. A cluster of eosinophils is at the center. H\&E, $\times 400$. (c) Ultrastructural examination of the infiltrating cells demonstrates Birbeck granules in the cytoplasm. Electron microscopy, $\times 21,500$.

10-year-old brother, ill from chronic liver failure with portal hypertension and jaundice, had a liver transplant at our institution several mon th s prior to his sister. His native liver weighed $1025 \mathrm{~g}$. It was cirrhotic and bile stained with ectatic hilar portal vein branches. The extrahepatic ducts were dilated and focally collapsed so that their walls formed papillary projections in to the lumen. There was diffuse hepatocanalicular cholestasis and marked ductular 
proliferation. Many neocholangioles had bile plugs and were surrounded by neutrophils, and occasional ducts had complex, irregular profiles. Most portal triads were sclerotic and without ducts; several had prominent arteries and thick-walled veins. The parenchyma had pseudoglandular transformation, focally prominent Mallory's hyaline, and pigmented Kupffer cells lining sinusoids. A $2.0-\mathrm{cm}$ regenerative nodule was present in the right lobe. The features in his liver were complex and perhaps best classified as Caroli's syndrome, that is, ductal plate malformation of the congenital hepatic fibrosis type with extrahepatic biliary involvement [9]. Langerhans' cells were not evident in the organ or elsewhere in the child, although the clinical data were likewise limited and a wedge biopsy performed during infancy was not available for review.

\section{DISCUSSION}

We report a case of $\mathrm{LCH}$ in a $2 \frac{1}{2}$-year-old Greek girl who underwent liver transplantation for progressive jaundice and portal hypertension. The explanted liver had biliary cirrhosis with sclerosing cholangitis and a Langerhans' cell lesion confined to the extrahepatic duct. Scattered S-100-positive dendritic cells in the portal triads are not unique to $\mathrm{LCH}$, although sheets and large clusters probably are [10]. Only the demonstration of Birbeck granules or surface CDla antigen, both demonstrated in this case, fulfills the requirement for a definitive diagnosis of LCH [11].

Single-system disease, other than skin or bone, is unusual in an infant. In fact, hepatic involvement in LCH seems to occur only in patients with multifocal or disseminated disease [12]. The diagnosis of multisystem organ involvement was not actively pursued in this patient after transplantation; a skeletal survey, water deprivation test, and urinary vasopressin levels were not performed. Although signs of diabetes insipidus were not evident, hypothalamic-pituitary involvem ent cannot be totally excluded [13]. Clinical information prior to admission to our institution was limited. Routine pre- and posttransplantation treatment, however, provided the following data: normal chest and abdominal radiographs, normal abdominal ultrasound examination, no lymphadenopathy, normal urine osmolality. There was no history of skin lesions, pulmonary disease, bone pain, exoph thalmos, polyuria, polydypsia, or aural discharge. From the available information, this case appears to represent $\mathrm{LCH}$ confined to the extrahepatic bile duct.

When LCH involves the liver, patients may show no dysfunction or present with hepatosplenomegaly, jaundice, portal hypertension, or abnormal liver function tests, particularly hypoalbuminemia. Pathologic features include histiocytic infiltration and proliferation in portal and sinusoidal 
regions with variable degrees of cholestasis and ductular proliferation, resulting in triaditis and fibrosis and often terminating as biliary cirrhosis [3, 12, 14, 15]. Circumscribed lesions resembling eosinophilic granuloma are unusual and percutaneous needle biopsies may be nondiagnostic [15]. This may be due in part to the preferential involvement of large-caliber bile ducts that are not represented on a needle biopsy.

Infiltration of large bile ducts by histiocytes is one cause of obstructive biliary cirrhosis in $\mathrm{LCH}[2,4,5,12]$. Cholangiograms in these patients have demonstrated changes of sclerosing cholangitis including irregular duct walls, filling defects, strictures, and dilatations of the extra and intrahepatic biliary tree.

Two and one-half years after transplantation, our patient is without evidence of LCH or sclerosing cholangitis in the allograft. She continues to receive Tacrolimus (FK506) immunosuppression. Or thotopic liver transplantation has been successful treatment for children with severe liver disease complicating LCH [16-22]. Recurrent disease in the allograft has not been reported.

The im munosuppressive agents used after transplantation may be helpful in preventing the return of disease by inhibiting the cellular immune response and cytokine-mediated cellular activation implicated in the pathogenesis of LCH. Cyclosporin A (CSA) has been tried as alternative treatment for LCH [23]. Tacrolimus, with corresponding but more potent action than CSA [24], has been used successfully in the treatment of a variety of autoimmune diseases [25-27] and should have similar immunomodulatory effects on LCH when used in the posttransplantation setting. However, in addition to preventing rejection and hepatic relapse, immunosuppression in this patient (and her brother) may have thwarted other unidentified LCH lesions.

The familial component of the liver disease is enigmatic. Pre- or postmortem examination was not performed on the sister of this patient, who was reported to have died in infancy from "liver failure." The brother's liver had features of Caroli's syndrome, prompting a search for fibrocystic disease in other organs. A renal ultrasound examination iden tified solitary, 1.0 -cm cysts in both the right and left kidneys. Chromosomal linkage analysis for the ARPCKD gene [28, 29] was performed in this family and was noninformative.

The relationship of $\mathrm{LCH}$ and liver disease in our patient is intriguing and suggests several explanations. First, Langerhans' cell histiocytosis of the bile duct is etiological, resulting in liver disease that is manifest in these siblings at different stages. Both children presen ted with jaundice at birth, suggesting a fetal onset. Histopathology of the liver originating with the fetal type of biliary atresia, viewed many years after a successful Kasai procedure, can resemble congenital hepatic fibrosis [30]. The ductal plate malformation is a consequence of damage to an immature biliary tree. These observations 
influenced Desmet's [30] suggestion that congenital hepatic fibrosis may represent an "arrested biliary atresia"; when early-onset obstruction is alleviated and the child allowed to grow, a ductal plate malformation, not biliary atresia, results. The livers from both siblings had characteristics of congenital hepatic fibrosis and sclerosing cholangitis. Hypothetically, LCH originated in utero; as the lesions matured (self-limited), Langerhans' cells disappeared and the ensuing fibrosis progressed to cirrhosis.

Second, a Langerhans' cell granuloma in our patient may be an incidental finding and unrelated to the pathogenesis of the as yet undefined and probably familial liver disease. The chance simultaneous occurrence of two unusual entities seems unlikely.

Most plausible is that LCH is "secondary" or "reactive," suggested by the timing and unifocal involvement. The association of LCH with malignant neoplasms is a rare but well-recognized event most frequently reported as concurrent lymphoma or lung carcinoma in the case of solid tumors [31-34]. LCH in these cases differs from "primary" LCH in its clinical presentation and has been considered by various authors as an incidental finding, a localized reactive phenomenon, or, when therapy can be excluded from the association, as part of a generalized immune derangement.

Lymphokines and proinflammatory cytokines acting as autocrine and/ or paracrine growth factors have been implicated in the pathogenesis of LCH and may account for the intermingling of two processes. The pattern of cytokines detected in LCH lesions is consistent with local activation of $\mathrm{T}$ lymphocytes and other inflammatory leukocytes [35]. A presently un recognized stimulus, but perhaps a virus, may be responsible for the activation, leading to both cytokine production and aberrant cellular adhesion molecule expression, a recently hypothesized mechanism for the abnormal homing of LCH cells [36]. A similar mechanism may unite our patient's sclerosing cholangitis and LCH.

Sclerosing cholangitis in children is associated with underlying diseases in $75 \%-80 \%$ of the cases; the remainder are considered idiopathic $[21,37]$. Various etiologies including inflam matory bowel disease, autoimmune hepatitis, and immunodeficiency states are implicated. Sclerosing cholangitis following liver involvement as part of disseminated LCH accounts for $15 \%-25 \%$ of the cases. Whether the LCH in our patient was primary or secondary, this case uniquely suggests that LCH can affect the extrahepatic bile ducts in isolation. In some instances, idiopathic sclerosing cholangitis may be late, hence undiagnosable, LCH. Early diagnosis is important because the biliary disease is refractory to therapy. 


\section{REFERENCES}

1. Willman CL, Busque L, Griffith BB, et al. Langerhans'-cell histiocytosis (histiocytosis-X) - a clonal proliferative disease. N Engl J Med 1994;331:154-60.

2. Heitner R, Mouton S, Rabinowitz L, Rosen EU. Type I histiocytosis X presenting as biliary atresia. A case report. S Afr Med J 1978;53:768-70.

3. LeBlanc A, Hadchouel M, Jehan P, Odievre M, Alagille D. Obstructive jaundice in children with histiocytosis X. Gastoenterology 1981;80:134-9.

4. Jones MB, Voet R, Pagani J, Lotysch M, O'Connell T, Koretz RL. Multifocal eosinophilic granuloma involving the common bile duct: Histologic and cholangiographic findings. Gastroenterology 1981; 80:384-9.

5. Thompson HH, Pitt HA, Lewin KJ, Longmire WP. Sclerosing cholangitis and histiocytosis X. Gut 1984;25:526-30.

6. Pirovino M, Jeanneret C, Lang RH, Luisier J, Bianchi L, Spichtin H. Liver cirrhosis in histiocytosis X. Liver 1988;8:293-8.

7. Squires RH, Weinberg AG, Zwiener RJ, Winick N. Langerhans' cell histiocytosis presenting with hepatic dysfunction. J Pediatr Gastroenterol Nutr 1993;16:190-3.

8. Krenacs L, Tiszalvicz L, Krenacs T, Boumsell L. Immunohistochemical detection of CD 1 a antigen in formalin-fixed and paraffin-embedded tissue sections with monoclonal antibody O10. J Pathol 1993; 171:99-104.

9. Desmet VJ. The cholangiopathies. In: Suchy FJ, ed., Liver Disease in Children. St. Louis: C.V. Mosby, 1994;157-65.

10. Dem etris AJ, Severs C, Kakizoe S, Oguma S, Starzl TE, Jaffe R. S-100 protein positive dendritic cells in primary biliary cirrhosis and other chronic inflammatory liver diseases. Am J Pathol 1989;134:741-7.

11. Writing Group of the Histiocyte Society. Histiocytosis syndromes in children. Lancet 1987;1:208-9.

12. Favara BE, McCarthy RC, Mierau GW. Histiocytosis X. Hum Pathol 1983;14:663-76.

13. Dunger DB, Broadbent V, Yeoman E, et al. The frequency and natural history of diabetes insipidus in children with Langerhans-cell histiocytosis. N Engl J Med 1989;321:1157-62.

14. Grosfeld JL, Fitzgerald JF, Wagner VM, Newton WA, Baehner RL. Portal hypertension in infants and children with histiocytosis X. Am J Surg 1976;131:108-13.

15. Heyn RM, Hamoudi A, Newton WA. Pretreatment liver biopsies in 20 children with histiocytosis X: A clinicopathologic correlation. Med Pediatr Oncol 1990;18:110-18.

16. Stieber AC, Sever C, Starzl TE. Liver transplantation in patients with Langerhans' cell histiocytosis. Transplantation 1990;50:338-40.

17. Mahmoud H, Gaber O, Wang W, Whitington G, Vera S, Murphy SB. Successful orthotopic liver transplantation in a child with Langerhans cell histiocytosis. Transplantation 1991;51:278-80.

18. Conception W, Esquivel CO, Terry A, et al. Liver transplantation in Langerhans' cell histiocytosis (histiocytosis X). Semin Oncol 1991;18:24-8.

19. Rand EB, Whitington PF. Successful orthotopic liver transplantation in two patients with liver failure due to sclerosing cholangitis with Langerhans cell histiocytosis. J Pediatr Gastroenterol Nutr 1992; 15:202-7.

20. Sommerauer JF, Atkison P, Andrews W, Moore P, Wall W. Liver transplantation for Langerhans' cell histiocytosis and immunomodulation of disease pre- and posttransplant. Transplant Proc 1994; 26:178-9.

21. Debray D, Pariente D, Urvoas E, Hadchouel M, Bernard O. Sclerosing cholangitis in children.J Pediatr 1994;124:49-56.

22. Zandi P, Panis Y, Debray D, Bernard O, Houssin D. Pediatric liver transplantation for Langerhans' cell histiocytosis. Hepatology 1995;21:129-33.

23. Mahmoud HH, Winfred CW, Murphy SB. Cyclosporin therapy for advanced Langerhans cell histiocytosis. Blood 1991;77:721-5.

24. Andersson J, Nagy S, Groth CG, Andersson U. Effects of FK506 and cyclosporin A on cytokine production studied in vitro at a single-cell level. Immunology 1992;75:136-42. 
25. Thomson AW, Starzl TE. FK506 and autoimmune disease: Perspective and prospects. Autoimmunity 1992;12:303-13.

26. Kai N, Motojima K, Tsunoda T, Kanematsu T. Prevention of insulitis and diabetes in nonobese diabetic mice by administration of FK506. Transplantation 1993;55:936-40.

27. Van Thiel DH, Wright H, Carroll P, et al. Tacrolimus: A potential new treatment for autoimmune chronic active hepatitis: Results of an open-label preliminary trial. Am J Gastroen terol 1995;90:771-6.

28. Guay-Woodford LM, Muecher G, Hopkins SD, et al. The severe perinatal form of au tosomal recessive polycystic kidney disease maps to chromosome 6p21.1-p12: Implications for genetic counseling. Am J Hum Genet 1995;56:1101-7.

29. Zerres K, Mucher G, Bachner L, et al. Mapping of the gene for autosomal recessive polycystic kidney disease (ARPKD) to chromosome 6p21-cen. Nat Genet 1994;7:429-32.

30. Desmet VJ, Callea F. Cholestatic syndromes of infancy and childhood. In: Zakim D, Boyer T, eds. Hepatology. A Textbook of Liver Disease. 2nd ed. Philadelphia: W. B. Saunders, 1990;1355-95.

31. Kjeldsberg CR, Kim H. Eosinophilic granuloma as an incidental finding in malignant lymphoma. Arch Pathol Lab Med 1980;104:137-40.

32. Burns BF, Colby TV, Dorfman RF. Langerhans' cell granulomatosis (histiocytosis X) associated with malignant lym phomas. Am J Surg Pathol 1983;7:529-33.

33. Neumann MP, Frizzera G. The coexistence of Langerhans' cell granulomatosis and malignant lym phoma may take different forms: Report of seven cases with a review of the literature. Hum Pathol 1986;1 7:1060-5.

34. Egeler RM, Neglia JP, Puccetti DM, Brennan CA, Nesbit ME. Association of Langerhans cell histiocytosis with malignant neoplasms. Cancer 1993;71:865-73.

35. Kannourakis G, Abbas A. The role of cytokines in the pathogenesis of Langerhans cell histiocytosis. Br J Cancer 1994;70 (suppl):S37-40.

36. de Graaf JH, Tamminga RYJ, Kamps WA, Timens W. Expression of cellular adhesion molecules in Langerhans cell histiocytosis and normal Langerhans cells. Am J Pathol 1995;147:1 161-71.

37. Sisto A, Feldman P, Garel L, et al. Primary sclerosing cholangitis in children: Study of five cases and review of the literature. Pediatrics 1987;80:918-23. 